\title{
Determinants of health-related quality of life: a cross-sectional investigation in physician-managed anticoagulated patients using vitamin $\mathrm{K}$ antagonists
}

Arianna Magon ${ }^{1 *}$, Cristina Arrigoni ${ }^{2}$, Marco Moia ${ }^{3}$, Michela Mancini ${ }^{4}$, Federica Dellafiore ${ }^{5}$, Duilio F. Manara ${ }^{6}$ and Rosario Caruso ${ }^{5}$

\begin{abstract}
Background: Literature has paid little attention in describing the specific contribution of each modifiable and nonmodifiable characteristics on health-related quality of life (HRQOL) in physician-managed anticoagulated patients using vitamin K antagonists (VKAs). To describe how patients' treatment-specific knowledge, health literacy, treatment beliefs, clinical, and socio-demographic characteristics influence HRQOL in Italian physician-managed anticoagulated patients using VKAs.

Methods: Cross-sectional multicentre study with a consecutive sampling strategy, enrolling 164 long-term anticoagulated patients. Clinical and socio-demographic characteristics were collected from electronic medical records. Valid and reliable questionnaires were used to collect patients' treatment-specific knowledge, health literacy, beliefs about VKAs, physical and health perceptions.

Results: Obtaining and understanding health information (i.e., communicative health literacy) positively predicts both adequate mental $\left(\mathrm{OR}_{\text {adjusted }}=10.9 ; 95 \% \mathrm{Cl}=1.99-19.10\right)$ and physical $\left(\mathrm{OR}_{\text {adjusted }}=11.54 ; 95 \% \mathrm{Cl}=1.99-34.45\right)$ health perceptions. Conversely, the ability to perform proper health decision making (i.e., critical health literacy) was associated with lower rates of adequate mental health perception $\left(\mathrm{OR}_{\text {adjusted }}=0.13 ; 95 \% \mathrm{Cl}=0.03-0.63\right)$. Further, age negatively predicted physical health perception $\left(\mathrm{OR}_{\text {adjusted }}=0.87 ; 95 \% \mathrm{Cl}=0.81-0.93\right)$.

Conclusions: Health literacy plays an interesting role in predicting HRQoL. The relationship between critical health literacy and mental health perception could be influenced by some psychological variables, such as distress and frustration, which could be present in patients with higher levels of critical health literacy, as they could be more inclined for self-monitoring. For this reason, future research are needed to identify the most suitable patients' profile for each OAC-management model, by longitudinally describing the predictive performance of each modifiable and non-modifiable determinant of HRQOL.
\end{abstract}

Keywords: Health literacy, Oral anticoagulants, Predictors, Quality of life

\footnotetext{
* Correspondence: arianna.magon@grupposandonato.it

'Department of Biomedicine and Prevention, University of Rome Tor Vergata,

Via Montpellier, 1 - 00133 Rome, Italy
}

Full list of author information is available at the end of the article

\section{$\triangle B M C$}

C C The Author(s). 2020 Open Access This article is licensed under a Creative Commons Attribution 4.0 International License, which permits use, sharing, adaptation, distribution and reproduction in any medium or format, as long as you give appropriate credit to the original author(s) and the source, provide a link to the Creative Commons licence, and indicate if changes were made. The images or other third party material in this article are included in the article's Creative Commons licence, unless indicated otherwise in a credit line to the material. If material is not included in the article's Creative Commons licence and your intended use is not permitted by statutory regulation or exceeds the permitted use, you will need to obtain permission directly from the copyright holder. To view a copy of this licence, visit http://creativecommons.org/licenses/by/4.0/ The Creative Commons Public Domain Dedication waiver (http://creativecommons.org/publicdomain/zero/1.0/) applies to the data made available in this article, unless otherwise stated in a credit line to the data. 


\section{Background}

Oral anticoagulation (OAC) is a lifelong treatment that involves roughly $2 \%$ of the western population [1]. Specifically, $\mathrm{OAC}$ is mainly indicated in non-valvular atrial fibrillation to prevent the incidence of ischemic stroke, as well as in other medical conditions that are associated with thromboembolic complications, such as the deep vein thrombosis [2]. An inadequate anticoagulation control is also associated with adverse events, which are severe bleeding, thromboembolic events, and mortality [3]. The most frequent adverse event is severe bleeding, showing an incidence ranging from 2 to $5 \%$ yearly, without significant differences between countries [4]. Thromboembolic complications associated with inadequate anticoagulation control show a yearly incidence of roughly $2 \%$ [5]. Mortality in anticoagulated patients is mainly associated with fatal bleeding, showing an incidence ranging from 0.5 to $1 \%$ yearly $[3,4]$.

Vitamin $\mathrm{K}$ antagonists (VKAs) have been the cornerstone of OAC for more than five decades [6]. Thus far, VKAs are the most widely used drugs for OAC for selected patients when the use of direct oral anticoagulants (DOACs) is not recommended-e.g., patients with rheumatic mitral valve disease in atrial fibrillation and/ or a mechanical heart valve prosthesis [7]. The main challenges of OAC with VKAs are given by the requirements to maintain an adequate anticoagulation control, as several changes in lifestyle habits are required, such as dietary restriction, drug interactions and frequent blood monitoring $[1,8]$.

Literature shows two main possible strategies for OAC management: Physician-managed (i.e., usual care approach) and self-monitoring models [9]. Self-monitoring models, for their part, encompass patient self-testing and self-management: In self-testing, patients can have their test result managed by their healthcare provider; conversely, in self-management, patients can interpret their international normalized ratio (INR) result, and adjust their own dose of anticoagulant accordingly [10]. Despite self-monitoring models are a safe option for suitable patients of all ages [9], physician-managed model is still the most used approach for managing VKAs [11]. However, empirical evidence and meta-analysis synthesis showed that physician-managed model has been associated with lower levels of health-related quality of life (HRQoL) than the ones reported for self-monitoring [9, 12-14]. The interpretation of the observed differences referred to HRQoL has not found a consensus yet, supporting the hypothesis that suitable patients to selfmonitoring receive more benefits when they are able to express their feeling of empowerment in managing their therapy [9].

HRQoL is an important outcome for anticoagulated patients, acknowledging that higher levels of HRQoL are associated with higher adjustment to treatment [15].
HRQoL in anticoagulated patients is generally adequate, even if there is still room for improvement $[14,16]$. The individual characteristics that can be changed to achieve an improvement of HRQoL are defined as modifiable determinants, while fixed factors of an individual (e.g. genetic, age) are defined as unmodifiable determinants [17]. Literature has already shown that patients' treatmentspecific knowledge, health literacy, and treatment beliefs are the most described modifiable determinants of clinical outcomes and treatment adherence [18-20].

Treatment-specific knowledge was described as the level of patients' awareness about risks and benefits of OAC [21] being also reported as a positive determinant of anticoagulation control [22] and being associated with better treatment adherence [19]. Furthermore, treatment-specific knowledge and adherence to OAC were described to be associated also with treatment beliefs [23]. Specifically, beliefs are defined as patients' concerns for treatment, and their understanding of the necessity of being treated with OAC [23]. Lastly, health literacy was defined as an individual's capacity to obtain, understand, and function the basic information and services to best manage his or her health, and engage in proper decision-making [24]. Previous research reported that anticoagulated patients with low health literacy were less adherent to OAC, exhibiting an increased risk of complication and disease-related mortality [25].

Thus far, it is not clear whether treatment-specific knowledge, health literacy, and treatment beliefs maintain their effects also in modulating the levels of HRQoL in anticoagulated patients, beyond their role in determining clinical outcomes [26]. In fact, previous research described knowledge, health literacy, and beliefs as potential modifiable determinants of HRQoL [26]. Research aimed at describing the modifiable determinants of HRQoL is pivotal for anticoagulated patients, as those determinants could be susceptible of improvement by evidence-grounded educational strategies [14, 26]. However, the role of those determinants in modulation HRQoL still remains less described than the effects of non-modifiable determinants in influencing HRQoL of anticoagulated patients. This gap is particularly important for physician-managed anticoagulated patients using VKAs, as they seem to report lower level of HRQoL than patients managed using self-monitoring [12-14]. Therefore, we aimed to identify the determinants of HRQoL in physician-managed anticoagulated patients using VKAs, highlighting the specific contribution of each non-modifiable and modifiable variable in modulating HRQoL.

\section{Methods}

An observational study was conducted involving two anticoagulation clinics (ACs) in the north of Italy from 
January 2019 to July 2019. The 'STrengthening the Reporting of OBservational studies in Epidemiology' (STROBE) checklist was used as a guide for the study reporting (see Additional file 1).

A convenience and consecutive sampling was used to enroll adult patients with a steady coagulation profile and able to complete self-reported questionnaires through a cross-sectional data collection. A good general rule of thumb for determining desirable sample size for studies involving self-report questionnaires is to consider a minimum of 50 participants per domain to allow an adequate variation of the measurements [27]. In this study, the theoretical construct with higher number of domains was given by health literacy, as it encompasses three different sub-measurements for functional, communicative, and critical health literacy. For this reason, we calculated the desirable sample size considering the number of domains included in the Health Literacy Questionnaire (HLQ), which is described in the measurements' paragraph $\left[\left(\mathrm{n}_{\text {domains }}=3\right) * 50\right.$ patients $=150$ patients]. According with previous research with a similar data collection approach [28], we expected a hypothetical response rate of $70 \%$. Thus, we invited to participate in this study a total of 195 adult anticoagulated patients.

In accordance with previous research about HRQoL in real-world anticoagulated population [29], the inclusion criteria for this study were: Patients aged $\geq 18$ years, in long-term treatment with VKAs (for at least 3 months) using physician-managed model, speaking fluently Italian. The exclusion criteria were: Patients short-term treated ( $<6$ months), patients who had to interrupt the treatment for a surgery in the last 3 months, with serious comorbidities (Charlson Comorbility Index $[\mathrm{CCI}]>4$ ), and with cognitive impairment (Six Item Screener test [SIS] <4). Data collection was performed using paperbased case report form (CRF) in the outpatient settings of each involved hospital, and the questionnaires' compilation required roughly $10 \mathrm{~min}$.

\section{Measurements}

Socio-demographic and clinical data (i.e., non-modifiable determinants) were detected from electronic medical records in accordance with the current guidelines, and previous research aimed at describing the anticoagulated population $[7,30]$. Socio-demographics were age, sex, marital status, educational level, and occupation. Clinical variables were time in $\mathrm{OAC}$, clinical indication for $\mathrm{OAC}$, time in therapeutic range (TTR) computed according to Rosendaal method, anamnesis of thromboembolic or bleeding complications in the last 3 months. Modifiable determinants (i.e., knowledge, beliefs and health literacy) and HRQoL were assessed through valid and reliable self-reported questionnaires available in Italian, which were Italian Anticoagulation Knowledge Tool (I-AKT) [31], Health Literacy Questionnaire (HLQ) [32], Beliefs about Medicine Questionnaire (BMQ) [33], and Short Form survey (SF-12) [34]. These questionnaires provided a measurement of patients' perceptions about their clinical condition and beliefs related to OAC [35].

Specifically, the Italian Anticoagulation Knowledge Tool (I-AKT) was used to measure the treatmentspecific knowledge [21, 31]. It encompasses two section: the first section $(n=20$ item) assesses the general anticoagulation knowledge for any kind of anticoagulants, while the second one $(n=8$ item) is specific for the treatment with VKAs. The percentage rate of correct answers was computed into a final score ranging from 0 to $100 \%$. In this study internal consistency reliability was satisfactory, as Cronbach's $\alpha$ was equal to 0.738 for the overall scale.

Health Literacy Questionnaire (HLQ) is a multidimensional tool composed by 44 items, which could be categorized in three main domains in accordance with Nutbeam's theory: functional, communicative, and critical literacy [32, 36]. These domains measure: (a) The ability of patients in being able to use basic skills of daily life functioning, such as writing and reading (i.e., functional health literacy), (b) the ability to obtain and understand health information (i.e., communicative health literacy), and (c) to perform a proper health decision making (i.e., critical health literacy). Each domain has a maximum score on 5-point Likert scale, and higher scores indicate better levels of health literacy [32]. In this study internal consistency reliability was adequate for each domain, exhibiting the following Cronbach's $\alpha$ for each domain: functional health literacy = 0.773 ; communicative health literacy $=0.945$; critical health literacy $=0.900$.

Beliefs about Medicines Questionnaire (BMQ) encompasses two sections related to concerns $(n=6$ item) and necessity referred to the drug prescription $(n=5$ item) from the patients' perspective. The first domain assesses patients' anxiety for VKAs, while the second domain assesses the therapeutic need as recognized by patients. The final score was computed on 5-point Likert scale for each domain [33]. In this study internal consistency reliability was adequate for each domain, showing Cronbach's $\alpha$ equal to 0.799 for the domain of concerns, and 0.794 for the domain of necessity.

Finally, the short form survey (SF-12) was used to assess HRQoL. It encompasses physical component summary (PCS12), and mental component summary (MCS12) using a standardized score ranging from 0 to 100 , wherein higher value indicates a more favorable health perception. According with previous research [37], it is possible to dichotomize the scores through an adequate versus an inadequate $\mathrm{HRQ}$ oL if we consider 
the median split strategy [34] acknowledging that the median scores of general Italian population, clustered by different age ranges, were previously published [38]. In this study, both components showed adequate internal consistency with Cronbach's $\alpha$ equal to 0.699 for PCS12 and 0.687 for MCS12.

\section{Ethical considerations}

The institutional review board of reference of each involved centers approved the study (n. 88/INT/2018). The research methodology was performed in accordance to the ethical values of declaration of Helsinki, good clinical practice (GCP) recommendations, and European law on data privacy (GDPR 2016/679 for non-interventional studies). A written informed consent form was requested to each eligible patients before the inclusion into the study. All participants were full informed about the aims and the method of the study, as well as about the confidentiality of their responses.

\section{Statistical analysis}

The collected variables were preliminary checked for possible missing data, outliers or errors through an analysis of frequency distribution. Qualitative variables were synthetized using frequency and percentage. Quantitative variables were initially assessed for normality using the analysis of skewness and kurtosis, followed by Shapiro-Wilk test. We employed mean \pm standard deviation (SD) for the normally distributed quantitative variables. The determinants of adequate HRQoL were assessed through two logistic regression (LR) models within the framework of generalized linear models. A median split approach was used to dichotomize PCS12 and MCS12, by considering the median values previously described among Italians with an age $\geq 65$ years [38]. Accordingly, PCS12 scores lower than 44.1 were considered as indicating inadequate physical health, while MCS12 scores lower than 46.4 were considered as indicating inadequate mental health. LR models were run considering (a) the correlational analysis interpretations in the first comparisons between the dichotomized PCS12, MCS12 with the collected individual-level variables (i.e., socio-demographic, clinical, knowledge, health literacy, and beliefs), and (b) the potential role of each independent variable considering previous studies [29, $39,40]$. Variables exhibiting point biserial correlation coefficient $\left(\mathrm{r}_{\mathrm{pb}}\right)$ with $p$-value $\leq 0.15$ were included into the LR models as independent variables [41]. Subsequently, PCS12 and MCS12 were employed as dichotomous outcomes in the logistic regression (LR) models, after the assessment for possible collinearity between the identified independent variable by checking the strength of their bivariate associations, which should not exceed 0.45 [42]. The goodness of fit for each LR model was determined using the Hosmer-Lemeshow test and Nagelkerke's pseudo- $R^{2}$. The independent variables were entered simultaneously into the models for examining each variable's relatively unique contribution to HRQoL. Statistical analysis was run through Statistical Package for the Social Sciences version 22 (IBM Corporation), with a two-tailed significance value set at 0.05 .

\section{Results \\ Sample}

A total of 164 patients were enrolled in this study (response rate $=84.1 \%)$. The majority of patients were males $(n=107$; $65.2 \%)$, with higher frequency of secondary educational level $(n=83 ; 50.6 \%)$, showing high rates of retired workers $(n=$ $136 ; 82.8 \%)$, with the mean (SD) of their age equal to 74 years $(\mathrm{SD}=10.2)$. The majority of patients were in treatment for more than 3 years $(n=145 ; 88.5 \%)$, and atrial fibrillation was the main clinical indication for OAC $(n=61 ; 37.2 \%)$. Only $31.7 \%$ of the enrolled patients $(n=52)$ had a TTR higher than $70 \%$ computed in the last 3 months, and clinical complications in the same period occurred in $1.2 \%(n=2)$. Overall, socio-demographic and clinical data are summarized in Table 1.

\section{HRQoL and self-reported variables}

The self-report variables are described in Table 2. The sample exhibited a mean score of MCS12 equal to 48.3 $(\mathrm{SD}=8.9)$, significantly higher than PCS12 ( $P$-value< $0.001)$, which reported a mean score equal to $44.0(\mathrm{SD}=$ 9.6). Among the domains describing health literacy, the lowest mean scores were reported for critical health literacy (mean $=2.8 ; \mathrm{SD}=0.4 ; P$-value $<0.001$ ). Furthermore, patients' concerns about drugs were lower than their recognition of the therapeutic need to be adherent with $\mathrm{OAC}$, respectively the reported means were $3.4(\mathrm{SD}=0.8)$ and $3.9(\mathrm{SD}=0.6)(p$-value $<0.001)$. The knowledge about treatment showed that the mean of correct answers of IAKT was equal to $63.2 \%$ ( $\mathrm{SD}=12.8 \%$ ).

Table 3 describes the bivariate analysis used to identify the independent variables of the analysis for assessing the determinants of HRQoL. Adequate PCS12 (categorizing $1=$ adequate PCS12 and $2=$ inadequate PCS12) was more frequent when patients reported higher scores of functional health literacy $\left(\mathrm{r}_{\mathrm{pb}}=-.268 ; p\right.$-value $\left.=0.001\right)$, communicative health literacy $\left(\mathrm{r}_{\mathrm{pb}}=-.288 ; p\right.$-value $\left.<0.001\right)$, critical health literacy $\left(\mathrm{r}_{\mathrm{pb}}=-.255 ; p\right.$-value $\left.=0.001\right)$. Inadequate PCS12 was more frequent in patients with higher CCI $\left(\mathrm{r}_{\mathrm{pb}}=.185 ; p\right.$-value $\left.=0.018\right)$, in older patients $\left(\mathrm{r}_{\mathrm{pb}}=\right.$ .424; $P$-value $<0.001)$ and among unemployed or retired patients $\left(\mathrm{r}_{\mathrm{pb}}=.283\right.$; $p$-value $\left.<0.001\right)$. Furthermore, knowledge $\left(\mathrm{r}_{\mathrm{pb}}=.084 ; p\right.$-value $\left.=0.144\right)$, and concerns about drugs $\left(\mathrm{r}_{\mathrm{pb}}=.117 ; p\right.$-value $\left.=0.135\right)$ reported non-significant correlations, but exhibiting $P$-values lower than 0.15 . 
Table 1 Socio-demographic and clinical characteristics of the sample $(n=164)$

\begin{tabular}{|c|c|c|}
\hline & $n$ & $\%$ \\
\hline \multicolumn{3}{|l|}{ Socio-demographic variables } \\
\hline \multicolumn{3}{|l|}{ Sex } \\
\hline Male & 107 & 65.2 \\
\hline Female & 57 & 34.8 \\
\hline \multicolumn{3}{|l|}{ Marital status } \\
\hline Married & 120 & 73.6 \\
\hline Unmarried & 43 & 26.4 \\
\hline \multicolumn{3}{|l|}{ Education } \\
\hline Primary school & 73 & 44.8 \\
\hline Secondary school & 83 & 50.9 \\
\hline Academic education & 7 & 4.3 \\
\hline \multicolumn{3}{|l|}{ Occupation } \\
\hline Active worker & 25 & 15.3 \\
\hline Unemployed & 3 & 1.8 \\
\hline Retired & 136 & 82.9 \\
\hline \multicolumn{3}{|l|}{ Age } \\
\hline Age Years (mean; SD) & 74 & 10.2 \\
\hline \multicolumn{3}{|l|}{ Clinical variables } \\
\hline \multicolumn{3}{|l|}{$\pi \mathrm{R}$} \\
\hline$\geq 70 \%$ & 52 & 39.4 \\
\hline$<70 \%$ & 80 & 60.6 \\
\hline \multicolumn{3}{|l|}{ Time in treatment* } \\
\hline$<6$ months & 3 & 1.8 \\
\hline $7-12$ months & 3 & 1.8 \\
\hline$>12$ months & 12 & 7.4 \\
\hline$>36$ months & 145 & 89.0 \\
\hline \multicolumn{3}{|l|}{ Clinical condition for anticoagulation treatment* } \\
\hline $\mathrm{AF}$ & 61 & 37.6 \\
\hline $\begin{array}{l}\text { Heart valve prosthesis } \\
\text { (i.e., mitral or aortic valve replacement) }\end{array}$ & 38 & 23.4 \\
\hline VTE & 19 & 11.7 \\
\hline Stoke & 2 & 1.3 \\
\hline $\mathrm{Ml}$ & 9 & 5.6 \\
\hline Others & 33 & 20.4 \\
\hline \multicolumn{3}{|l|}{ Comorbidity (CCI) } \\
\hline No comorbidity & 3 & 1.9 \\
\hline $1-2$ & 116 & 71.6 \\
\hline $3-4$ & 43 & 26.5 \\
\hline \multicolumn{3}{|c|}{ Clinical complications (thromboembolic or haemorrhagic) } \\
\hline Yes & 2 & 1.2 \\
\hline No & 162 & 98.8 \\
\hline
\end{tabular}

TTR Time in Therapeutic Range, AF Atrial Fibrillation, VTE Venous Thromboembolism, MI Myocardial Infarction, $\mathrm{CCl}$ Charlson Comorbidity Index Note: Missing data were reported for marital status $(N=1)$, education $(N=1)$, TTR $(N=32)$, time in treatment $(N=1)$, clinical condition for anticoagulation treatment $(N=2)$, and comorbidity $(N=2)$
Conversely, adequate MCS12 scores (categorizing $1=$ adequate MCS12 and 2 = inadequate MCS12) were more frequent among patients with higher scores of functional $\left(\mathrm{r}_{\mathrm{pb}}=-.201 ; p\right.$-value $\left.=0.010\right)$ and communicative health literacy $\left(\mathrm{r}_{\mathrm{pb}}=-.221 ; p\right.$-value $\left.=0.004\right)$, and in younger patients $\left(\mathrm{r}_{\mathrm{pb}}=.207 ; p\right.$-value $\left.=0.008\right)$, being higher in active workers $\left(\mathrm{r}_{\mathrm{pb}}=.270 ; p\right.$-value $\left.=0.009\right)$.

\section{Determinants of HRQoL}

Table 4 shows the contribution of each non-modifiable and modifiable variable in modulating HRQoL. The odds of adequate PCS12 decreased by roughly $13 \%$ for each year a participant aged $\left(\mathrm{OR}_{\text {adjusted }}=0.873 ; 95 \% \mathrm{CI}=\right.$ $0.816-0.935 ; p$-value $<0.001)$. The odds of adequate PCS12 increases by more than 11 times for each increased score of communicative health literacy (OR adjusted $=11.545 ; 95 \% \mathrm{CI}=1.991-34.451 ; p$-value $=0.051$ ).

The odds of adequate MCS12 increases by approximately 11 times for each increased score of communicative health literacy $(\mathrm{OR}$ adjusted $=10.929 ; 95 \% \mathrm{CI}=1.999$ 19.102; $p$-value $=0.011)$. Furthermore, the odds of adequate MCS12 decreases by roughly $80 \%$ for each increased score of critical health literacy $(\mathrm{OR}$ adjusted $=$ $0.128 ; 95 \% \mathrm{CI}=0.026-0.628 ; p$-value $=0.011$ ).

\section{Discussion}

This study provided an overall description of the role of modifiable and non-modifiable determinants of HRQoL in physician-managed anticoagulated patients using VKAs. Among these, health literacy showed interesting effects in determining adequate PCS12 and MCS12. Broadly, promoting adequate levels of health literacy is a public health goal for ensuring equity of care, reduction of health costs, and better achievement of outcomes [24, 43], acknowledging that health literacy is a key indicator for evaluating the quality of care delivery $[44,45]$.

However, in our study, health literacy showed a paradoxical effect, as critical health literacy decreased the likelihood of achieving adequate mental health perception. In accordance with previous research, critical health literacy should predict more positive outcome, such as self-care and HRQoL [24, 46, 47]. In our study, we reported that patients with higher critical thinking abilities about their chronic treatment (higher levels of critical health literacy) reported lower levels of mental health perception. To interpret this paradoxical result, we hypothesized that the physician-managed model in managing OAC could influence the relationship between critical health literacy and mental health perception. In fact, patients with higher levels of critical health literacy are often those exhibiting higher desire to take control of their health management, including treatment [48, 49]. In other words, patients with higher critical health literacy are generally inclined for self-management, as 
Table 2 Descriptive statistics of Modifiable Determinants and HRQOL $(n=164)$

\begin{tabular}{lccc}
\hline & Mean & SD & $p$-value \\
\hline Health Literacy & 3.0 & 0.6 & $<0.001$ \\
Functional & 3.0 & 0.5 & \\
Communicative & 2.8 & 0.4 & \\
$\quad$ Critical & & & \\
Beliefs & 3.9 & 0.6 & \\
$\quad$ Necessity & 3.4 & 0.8 & \\
Concerns & & & \\
Health-related quality of Life & & 9.001 \\
PCS-12 & 44.0 & 9.6 & \\
MCS-12 & 48.3 & 8.9 & na \\
Knowledge & & 12.8 & \\
I-AKT & 63.2 & & \\
\hline PCS12 Physical Health Composite Score of treatment relat quality of life
\end{tabular}

PCS12 Physical Health Composite Score of treatment related quality of life, MCS12 Mental Health Composite Score of treatment related quality of life, IAKT Italian Anticoagulation Knowledge, na not applicable

they would like to take control of their own chronic condition [50]. This suggests, possibly explaining this result, that patients with high critical health literacy can experience more frustration and distress when they are managed using traditional models for OAC, inasmuch they are not actively involved in the therapeutic decisionmaking $[50,51]$. Notwithstanding, it should be empirically tested whether the patients with higher critical health literacy, managed using self-monitoring models, exhibit higher levels of mental health perception.
In this study, the levels of knowledge, health literacy, and recognition of the therapeutic need to be adherent with OAC are generally low. In accordance with previous evidence, more attention should thus be paid in improving the modifiable determinants of health through educational interventions, especially identifying patients that could have benefits from self-monitoring [19, 20, $23,52,53]$. In other words, the default use of the traditional OAC management model-as it happens in the real-world clinical practice in many countries-seems to meet poorly the requirements for optimizing patients' HRQoL through enhancing their knowledge, health literacy, and correct beliefs: One size (traditional OAC management) cannot fit all!

Thus far, the main recognized criteria to identify suitable patients for self-monitoring models were given by (a) anamnesis of adequate anticoagulation control, (b) motivation to be engaged in managing OAC through self-monitoring, (c) adequate treatment-specific knowledge, and (d) adequate cognitive functioning [7, 53]. That said, this study contributes to further understand which criteria could be useful in practice to identify suitable patients for self-monitoring, as per the role of health literacy in determining HRQoL. Health literacy was previously presented as a public health goal, explained within an integrated framework that encompasses knowledge, motivation, and cognitive functioning as personal determinants of each health literacy level (i.e., functional, communicative, and critical) [54]. This implies that the individual's health literacy levels are

Table 3 Correlations between modifiable-unmodifiable determinants and HRQOL (PCS12 \& MCS12)

\begin{tabular}{|c|c|c|c|c|}
\hline & \multicolumn{2}{|c|}{$\begin{array}{l}\text { PCS12 } \\
(1=\text { adequate; } 2=\text { inadequate })\end{array}$} & \multicolumn{2}{|c|}{$\begin{array}{l}\text { MCS12 } \\
(1=\text { adequate; } 2 \text { = inadequate })\end{array}$} \\
\hline & $r_{p b}$ & $p$-value & $r_{p b}$ & $\boldsymbol{p}$-value \\
\hline $\mathrm{CCl}$ & .185 & 0.018 & .010 & 0.896 \\
\hline Age & .424 & $<0.001$ & .207 & 0.008 \\
\hline Sex ( 1 = male; 2 = female) & -.005 & 0.947 & -.061 & 0.438 \\
\hline Marital Status ( $1=$ married; 2 = unmarried $)$ & .072 & 0.362 & -.039 & 0.622 \\
\hline $\begin{array}{l}\text { Education ( } 1=\text { education equal to primary school; } \\
2=\text { higher than primary school) }\end{array}$ & -.12 & 0.127 & .002 & 0.977 \\
\hline Occupation ( 1 = active workers; 2 = unemployed or retired $)$ & .283 & $<0.001$ & .270 & 0.009 \\
\hline Time in OAC & .048 & 0.545 & .03 & 0.703 \\
\hline TTR\% (1 = adequate; 2 = inadequate) & .098 & 0.273 & .059 & 0.172 \\
\hline I-AKT & .084 & 0.144 & .033 & 0.371 \\
\hline HLQ_Fun & -.268 & 0.001 & -.201 & 0.010 \\
\hline HLQ_Com & -.288 & $<0.001$ & -.221 & 0.004 \\
\hline HLQ_Cri & -.255 & 0.001 & -.068 & 0.388 \\
\hline BMQ_N & -.009 & 0.904 & -.070 & 0.371 \\
\hline BMQ_C & .117 & 0.135 & .026 & 0.739 \\
\hline
\end{tabular}

CCI Charlson Comorbidity Index, I-AKT Italian anticoagulation knowledge tool, HLQ health literacy questionnaire, BMQ beliefs medicine questionnaire 
Table 4 Determinants of an adequate PCS12 and MCS12 $(n=164)$

\begin{tabular}{|c|c|c|c|c|c|c|c|c|}
\hline & \multicolumn{4}{|c|}{ Adequate PCS-12 } & \multicolumn{4}{|c|}{ Adequate MCS-12 } \\
\hline & $\begin{array}{l}\text { OR } \\
\text { adjusted }\end{array}$ & $95 \% \mathrm{Cl}$ & & $p$-value & OR adjusted & $95 \% \mathrm{Cl}$ & & $p$-value \\
\hline \multicolumn{9}{|l|}{ Predictors } \\
\hline Comorbidity Index (CCI) & 0.834 & 0.552 & 1.259 & 0.255 & 1.132 & 0.763 & 1.679 & 0.538 \\
\hline Age & 0.873 & 0.816 & 0.935 & $<0.001$ & 0.949 & 0.896 & 1.006 & 0.080 \\
\hline $\begin{array}{l}\text { Education ( } 1 \text { = education equal to primary school; } \\
2=\text { higher than primary school) }\end{array}$ & 0.520 & 0.228 & 1.188 & 0.165 & 0.699 & 0.328 & 1.49 & 0.354 \\
\hline $\begin{array}{l}\text { Occupation }(1=\text { active workers; } \\
2=\text { unemployed or retired })\end{array}$ & 0.807 & 0.448 & 1.453 & 0.181 & 0.729 & 0.414 & 1.283 & 0.273 \\
\hline Tot I-AKT & 0.985 & 0.957 & 1.014 & 0.061 & 0.997 & 0.97 & 1.025 & 0.849 \\
\hline HLQ_Functional & 0.36 & 0.059 & 2.203 & 0.269 & 0.575 & 0.104 & 3.18 & 0.526 \\
\hline HLQ_Communicative & 11.545 & 1.991 & 34.451 & 0.051 & 10.929 & 1.999 & 19.102 & 0.011 \\
\hline HLQ_Critical & 0.729 & 0.14 & 3.796 & 0.708 & 0.128 & 0.026 & 0.628 & 0.011 \\
\hline BMQ_Concerns & 0.943 & 0.586 & 1.517 & 0.808 & 1.094 & 0.697 & 1.716 & 0.696 \\
\hline \multicolumn{9}{|l|}{ Model fit } \\
\hline Test di Hosmer e Lemeshow & 0.097 & & & & 0.391 & & & \\
\hline Pseudo- $R^{2}$ (Nagelkerke) & 0.391 & & & & 0.223 & & & \\
\hline
\end{tabular}

shaped as the result of the relationships between personal determinants and situational factors (e.g., healthcare and social contexts) [54]. For this reason, the assessment of health literacy as a pivotal criteria for identifying suitable patients for self-monitoring could be a strategic practical implication for the international healthcare providers' community, due to patients with higher ability to perform proper health decision making (i.e., critical health literacy) could be easily identified as suitable for self-monitoring models. Furthermore, the tools aimed at assessing health literacy levels are available in many languages, being also validated in different settings [55].

We found almost no significant relationships between HRQoL and sociodemographic and clinical characteristics, while previous evidence showed that worsen HRQoL was associated with being young, female, having lower education, and with higher comorbidity, being in short-term treatment (lower than 1 year), and with previous haemorrhagic complications [10, 12]. In our study, the age was the only sociodemographic determinant of physical health perception. This result is consistent with previous research $[16,56]$. Hence, further research should in-depth clarify how socio-demographics and clinical variables modulate health perception in anticoagulated patients over time, using longitudinally collected data.

\section{Study limitations}

This study has some limitations. Firstly, the adopted cross-sectional data collection using a limited sample did not provide information on the trajectory of HRQoL and its determinants over time, and possibly the associations between independent variables and outcomes were under-estimated. Secondly, the convenience sampling suggested caution in generalizing the results. Thirdly, the comparison between different OAC management models was not included in the study design, as only physician-managed anticoagulated patients were enrolled, acknowledging that self-monitoring models report a limited use in practice in the context of this study; however, future research should compare the effects of health literacy levels in modulating HRQoL between different OAC models. Furthermore, the role of the modifiable determinants of HRQoL could be contextspecific, as some cultural and social characteristics could influence how they interact with HRQoL. For this reason, cross-national research will be useful to overcome this limit. Finally, variables related to stress perception were not collected in this study: To better understand the paradoxical result given by the association between high levels of critical health literacy and lower levels of perceived mental health, future investigations should also keep into account the assessment of stress perception.

\section{Conclusions}

HRQoL in physician-managed VKAs anticoagulated patients seems to be associated with communicative and critical health literacy. Higher ability to obtain and understand health information about OAC is associated with more adequate physical and mental health perception. However, the patients' critical thinking about their treatment (critical health literacy) was associated with less adequate mental health perception. This result 
suggests that the relationship between critical health literacy and mental health perception can be influenced by some psychological variables, such as distress and frustration, which could be present in patients with higher levels of critical health literacy, as they could be the ones more inclined for self-monitoring, acknowledging their desire to take control of their health. This hypothesis should be empirically tested to understand whether critical health literacy could be considered as criteria for identifying suitable patients for self-monitoring, by comparing its role in predicting HRQoL between physicianmanaged and self-monitoring models. Future research should identify the most suitable patients' profile for each OAC-management model, by longitudinally describing the predictive performance of each modifiable and non-modifiable determinant of HRQoL.

\section{Supplementary information}

Supplementary information accompanies this paper at https://doi.org/10. 1186/s12955-020-01326-y.

Additional file 1. STROBE Statement-Checklist of items that should be included in reports of cross-sectional studies

\section{Abbreviations}

OAC: Oral anticoagulation; VKAs: Vitamin K antagonists; DOACs: Direct oral anticoagulants; HRQoL: Health related quality of life; PCS12: Physical component summary; MCS12: Mental component summary

\section{Acknowledgements}

The authors wish to thanks all participants in the study and three nursing students (Marika Errico; Valentina Giuranna; Alice Lobascio) for their contribution in data collection and data entry.

\section{Authors' contributions}

AM and RC conceptualized the study and performed statistical analysis. MM and FD assisted in data collection. AM and RC drafted the original manuscript and CA, MaM and DM assisted in writing and reviewing the manuscript. All authors read and approved the final manuscript.

\section{Funding}

This research was partially supported by "Ricerca Corrente" funding from Italian Ministry of Health to IRCCS Policlinico San Donato, and by Foundation "Insieme per Vita agli Anni" (no specific grant).

\section{Availability of data and materials}

All data generated or analyzed during this study are included in this published article. The datasets used during the current study are available from the corresponding author on reasonable request.

\section{Ethics approval and consent to participate}

This study was approved by Research \& Ethical Committee of San Raffaele Hospital (Italy) (Protocol 88/INT/2018 of 10th May 2018).

\section{Consent for publication}

Not Applicable.

\section{Competing interests}

The authors declare that they have no competing interests.

\section{Author details}

${ }^{1}$ Department of Biomedicine and Prevention, University of Rome Tor Vergata, Via Montpellier, 1 - 00133 Rome, Italy. ${ }^{2}$ Department of Public Health, Experimental and Forensic Medicine, Section of Hygiene, University of Pavia,
Pavia, Italy. ${ }^{3}$ Fondazione IRCCS Ca' Granda Ospedale Maggiore Policlinico, Angelo Bianchi Bonomi Hemophilia and Thrombosis Center and Fondazione Luigi Villa, Milan, Italy. ${ }^{4}$ Nursing Office, ASST Melegnano e della Martesana, Melzo, Italy. ${ }^{5}$ Health Professions Research and Development Unit, IRCCS Policlinico San Donato, San Donato Milanese, Milan, Italy. ${ }^{6}$ School of Nursing, Vita-Salute San Raffaele University, Milan, Italy.

Received: 22 January 2020 Accepted: 11 March 2020

Published online: 16 March 2020

\section{References}

1. Palareti $\mathrm{G}$, et al. Vitamin $\mathrm{K}$ antagonist therapy: changes in the treated populations and in management results in Italian anticoagulation clinics compared with those recorded 20 years ago. Intern Emerg Med. 2017;12: 1109-19.

2. Hart RG, Pearce LA, Aguilar MI. Meta-analysis: Antithrombotic therapy to prevent stroke in patients who have nonvalvular atrial fibrillation. Ann Intern Med American College of Physicians. 2007;146:857-67.

3. Navarro Navarro JL, Cesar JM, Fernández MA, Fontcuberta J, Reverter JC, Gol-Freixa J. Morbilidad y mortalidad en pacientes con tratamiento anticoagulante oral. Rev Esp Cardiol. 2007;60:1226-32.

4. Rubboli A. Incidence, clinical impact and risk of bleeding during oral anticoagulation therapy. World J Cardiol Baishideng Publishing Group Inc. 2011;3:351 [cited 2020 Feb 26] Available from: http://www.wjgnet.com/194 9-8462/full/v3/i11/351.htm

5. Poli D, Antonucci E, Cecchi E, Marcucci R, Liotta AA, Cellai AP, et al. Culprit factors for the failure of well-conducted warfarin therapy to prevent ischemic events in patients with atrial fibrillation: the role of homocysteine. Stroke. 2005;36:2159-63.

6. Zirlik A, Bode C. Vitamin K antagonists: relative strengths and weaknesses vs. direct oral anticoagulants for stroke prevention in patients with atrial fibrillation. J Thromb Thrombolysis. Springer US. 2017;43:365-79.

7. ESC. 2016 ESC Guidelines for the management of atrial fibrillation developed in collaboration with EACTS. Eur Heart J. 2016;37:2893-962.

8. Prisco D, et al. Italian intersociety consensus on DOAC use in internal medicine. Intern Emerg Med. 2017;12:387-406.

9. Heneghan C, Ward A, Perera R. Self-monitoring of oral anticoagulation: systematic review and meta-analysis of individual patient data. Lancet. 2012; 379:322-34

10. Jennings I, Kitchen D, Keeling D, Fitzmaurice D, Heneghan C. On behalf of the BCSH committee. Patient self-testing and self-management of oral anticoagulation with vitamin $\mathrm{K}$ antagonists: guidance from the British Committee for Standards in Haematology. Br J Haematol. 2014;167:600-7.

11. Baudo F, et al. Self-testing and self-monitoring of Oral anticoagulant therapy: consensus of the Italian Federation of Anticoagulation Clinics. J Haematol. 2003;88:1-10.

12. Mccahon D, Murray ET, Murray K, Holder RL, Fitzmaurice DA. Does selfmanagement of oral anticoagulation therapy improve quality of life and anxiety? Fam Pract. 2011;2011(28):134-40.

13. Siebenhofer A, Hemkens LG, Rakovac I, Spat S, Didjurgeit U. Selfmanagement of oral anticoagulation in elderly patients - effects on treatment-related quality of life. Thromb Res Elsevier Ltd. 2012;130:e60-6.

14. Ynsaurriaga FA, Peinado RP, Miguel J. Atrial fibrillation and quality of life related to disease and treatment : focus on anticoagulation. Futur Cardiol. 2014;10:381-93.

15. Calvert MJ, Freemantle N. Use of health-related quality of life in prescribing research. Part 1 : why evaluate health-related quality of life ? J Clin Pharm Ther. 2003;28:513-21.

16. Almeida GDQ, LDACB N, Carlos L, Passos S. Quality of Life analysis of patients in chronic use of oral anticoagulant : an observational study. Health Qual Life Outcomes. BioMed Central Ltd. 2011;9:91.

17. Megari K. Quality of life in chronic disease patients. Heal Psychol Res PAGE Press Publications. 2013;1:27.

18. LaRosa AR, Pusateri AM, Althouse AD, et al. Mind the gap: deficits in fundamental disease-specifc knowledge in atrial fibrillation. Int J Cardiol. 2019;292:272-6.

19. Rolls CA, Obamiro K, Chalmers L, Bereznicki L. The relationship between knowledge, health literacy, and adherence among patients taking oral anticoagulants for stroke thromboprophylaxis in atrial fibrillation. Cardiovasc Ther. 2017;35:1-8. 
20. Fang MC, Machtinger EL, Wang F, Schillinger D. Health literacy and anticoagulation-related outcomes among patients taking warfarin. J Gen Intern Med. 2006;21:841-6.

21. Obamiro KO, Chalmers L, Bereznicki LRE. Development and validation of an oral anticoagulation knowledge tool (AKT). PLoS One. 2016;11:1-10.

22. Winans ARMF, Rudd KM, Triller D. Assessing anticoagulation knowledge in patients new to warfarin therapy. Ann Pharmacother. 2010;44:1152-7.

23. Zhao S, Zhao HWX, et al. Factors influencing medication knowledge and beliefs on warfarin adherence among patients with atrial fibrillation in China. Patient Prefer Adherence. 2017;11:213-20.

24. Caruso $\mathrm{R}$, et al. Health literacy in type 2 diabetes patients: a systematic review of systematic reviews. Acta Diabetol. 2018;55:1-12.

25. Reading SR, Go AS, Fang MC, Singer DE, Liu ILA, Black MH, et al. Health literacy and awareness of atrial fibrillation. J Am Heart Assoc. 2017;6:1-10.

26. Perino $A C$, et al. Comparison of patient-reported care satisfaction, quality of warfarin therapy, and outcomes of atrial fibrillation: findings from the ORBIT-AF registry. J Am Hear Assoc. 2019;8:e011205.

27. Wilson Vanvoorhis CR, Morgan BL. Understanding power and rules of thumb for determining sample sizes. Tutor Quant Methods Psychol. 2007; 3(2):43-50.

28. Fincham JE. Response rates and responsiveness for surveys, standards, and the Journal. Am J Pharm Educ American Association of Colleges of Pharmacy.2008;72:43.

29. Benzimra M, Duracinsky M, Lalanne C, Aubert J, Chassany O, Aubin-auger I, et al. Real-life experience of quality of life, treatment satisfaction , and adherence in patients receiving oral anticoagulants for atrial fibrillation. Patient Prefer Adherence. 2018;12:79-87.

30. Antonucci E, Poli D, Tosetto A, Pengo V. The Italian START-register on anticoagulation with focus on atrial fibrillation. PLoS One. 2015;10:e0124719.

31. Magon A, Arrigoni C, Roveda T, Grimoldi P, Dellafiore F, Moia M. OKCR. Anticoagulation knowledge tool (AKT): further evidence of validity in the Italian population. PLoS One. 2018:13:1-14.

32. Osborne RH, Batterham RW, Elsworth GR, Hawkins M, Buchbinder R. The grounded psychometric development and initial validation of the health literacy questionnaire (HLQ). BMC Public Health. 2013;13:658.

33. Argentero $P$, et al. Validità e utilità della versione italiana del BMQ ( the beliefs about medicines questionnaire ) the beliefs about drug treatment. The Italian version. Epidemiol Psichiatr Soc. 2010;19:86-92.

34. DeCoster J, Gallucci M, Iselin A-MR. Best practices for using median splits, artificial categorization, and their continuous alternatives. J Exp Psychopathol. 2011;2:197-209.

35. Smith S, Weldring T. Patient-reported outcomes (PROs) and patient-reported outcome measures (PROMs). Heal Serv Insights. 2013;6:61-8

36. Nutbeam D. Health literacy as a public health goal: a challenge for contemporary health education and communication strategies into the $21 \mathrm{st}$ century. Health Promot Int. 2000;15:259-67.

37. Dellafiore F, Caruso R, Arrigoni C, Flocco SF, Giamberti A, Chessa M. Lifestyles and determinants of perceived health in Italian grown-up/adult congenital heart patients: a cross-sectional and pan-national survey. BMJ Open. 2019;9:1-7.

38. Gandek B, Ware JE, Aaronson NK, Apolone G, Bjorner JB, Brazier JE, et al. Crossvalidation of item selection and scoring for the SF-12 health survey in nine countries: results from the IQOLA project. J Clin Epidemiol. 1998;51:1171-8,

39. Scalçone I, Corbi A, Aparecida R, Dantas S, Rodrigues A. Health related quality of life of patients undergoing oral anticoagulation therapy. Rev Latino-Am Enferm. 2011;19:866-73.

40. Keita I, Aubin-auger I, Aubert J, Chassany O, Duracinsky M, Mahé I. Assessment of quality of life, satisfaction with anticoagulation therapy, and adherence to treatment in patients receiving long-course vitamin $\mathrm{K}$ antagonists or direct oral anticoagulants for venous thromboembolism. Patient Prefer Adherence. 2017;11:11:1625-34.

41. Bursac Z, Gauss CH, Williams DKHD. Purposeful selection of variables in logistic regression. Source Code Biol Med. 2008;3:17.

42. Dormann CF, Elith J, Bacher S, Buchmann C, Carl G, Carré G, et al. Collinearity: a review of methods to deal with it and a simulation study evaluating their performance. Ecography (Cop). 2013;36:27-46.

43. Hajat C, Stein E. The global burden of multiple chronic conditions : a narrative review. Prev Med Reports Elsevier. 2018;12:284-93.

44. Magnani J. et al. Health Literacy and Cardiovascular Disease: Fundamental Relevance to Primary and Secondary Prevention: A Scientific Statement From the American Heart Association. Circulation. 2018;138:e48-e74.
45. Dennison $C R$, et al. Adequate health literacy is associated with higher heart failure knowledge and self-care confidence in hospitaized patients. J Cardiovasc Nurs. 2012;26:359-67.

46. Panagioti M, Skevington SM, Hann M, Howells K, Blakemore A, Reeves D, et al. Effect of health literacy on the quality of life of older patients with long-term conditions : a large cohort study in UK general practice. Qual Life Res Springer International Publishing. 2018;25:1257-68.

47. Al Sayah F, Qiu W, Johnson JA. Health literacy and health-related quality of life in adults with type 2 diabetes: a longitudinal study. Qual Life Res. 2016; 25:1487-94.

48. Wilson PM. A policy analysis of the expert patient in the United Kingdom: self-care as an expression of pastoral power? Heal Soc Care Community. 2001;9:134-42.

49. Fox NJ, Ward KJ, O'Rourke AJ. The 'expert patient': empowerment or medical dominance? The case of weight loss, pharmaceutical drugs and the Internet. Soc Sci Med. 2005;60:1299-309.

50. Gadisseur APA, et al. Patient self-management of oral anticoagulant care vs management by specialized anticoagulation clinics : positive effects on quality of life. J Thromb Haemostatis. 2004;2:584-91.

51. Henwood F, Wyatt $S$, Hart A, Smith J. "Ignorance is bliss sometimes": constraints on the emergence of the "informed patient" in the changing landscapes of health information. Sociol Heal IIIn. 2003;25:589-607.

52. Garcia AC, et al. Relation between health literacy, self-care and adherence to treatment with oral anticoagulants in adults: a narrative systematic review. BMC Public Health. 2018;18:1157.

53. Magon A, Dellafiore F, Pittella F, Caruso R. Criteria and requirements of selfmonitoring pathways for the management of oral anticoagulant therapy: meta-narrative analysis of a systematic review. Ric e Prat. 2016;32:246-54.

54. Sørensen K, Van Den Broucke S, Fullam J, Doyle G, Pelikan J, Slonska Z, et al. Health literacy and public health: A systematic review and integration of definitions and models. BMC Public Health. 2012;12:80.

55. Liu H, Zeng H, Shen $Y$, Zhang F, Sharma M, Lai W, et al. Assessment tools for health literacy among the general population: a systematic review. Int J Environ Res Public Health MDPI AG. 2018;15(8):1711.

56. Kneeland PP. Current issues in patient adherence and persistence : focus on anticoagulants for the treatment and prevention of thromboembolism. Patient Prefer Adherence. 2010:4:51-60.

\section{Publisher's Note}

Springer Nature remains neutral with regard to jurisdictional claims in published maps and institutional affiliations.

Ready to submit your research? Choose BMC and benefit from:

- fast, convenient online submission

- thorough peer review by experienced researchers in your field

- rapid publication on acceptance

- support for research data, including large and complex data types

- gold Open Access which fosters wider collaboration and increased citations

- maximum visibility for your research: over $100 \mathrm{M}$ website views per year

At $\mathrm{BMC}$, research is always in progress.

Learn more biomedcentral.com/submission 